\title{
Gene Polymorphism of Solute Carrier 30 A8 (SLC30A8) in Type 2 Diabetes Mellitus
}

\author{
Fasil Ali ${ }^{1}$, Aarif Ali ${ }^{1}$, Showkeen Muzamil $^{2}$, Omer Khalil Baba ${ }^{2}$, \\ Aadil Ayaz ${ }^{3}$ and Mashooq Ahmad Dar ${ }^{1}$
}

\begin{abstract}
${ }^{1}$ Department of Clinical Biochemistry University of Kashmir, Srinagar-190006, J\&K, India ${ }^{2}$ Molecular Biology Lab, Division of Veterinary Biochemistry, Faculty of Veterinary Sciences \& Animal Husbandry, Sheri Kashmir University of Agricultural Science \& Technology-Kashmir (SKUAST-K), Srinagar, J\&K, India 190006.

${ }^{3}$ Department of Zoology and Biotechnology, HNBG University, Srinagar, Uttarakhand, India *Corresponding author
\end{abstract}

A B S T R A C T

\begin{tabular}{|l|}
\hline K e y w o r d s \\
Diabetes, Zinc- \\
transporter-8, \\
SLC30A8, \\
Susceptibility, \\
Resistance and \\
Insulin secretion. \\
\hline Article Info \\
\hline Accepted: \\
10 July 2017 \\
Available Online: \\
10 September 2017 \\
\hline
\end{tabular}

\section{Introduction}

Type 2 diabetes mellitus (T2D) is one of the common metabolic diseases demonstrated by hyperglycemia associated with defective insulin secretion or activity in $\beta$ cells. Today T2D is one of the major public health problems occurring globally. According to the recent reports, its worldwide incidence in adults is about $6 \%(1)$. The prevalence of diabetes is increasing worldwide and T2D occupies the sixth position in the number of deaths. The main reason of death is primarily related to complications associated with diabetes (2). The most common complications of T2D are: cardiovascular diseases, retinopathy, nephropathy and diabetic foot which may lead to limb imputation. Thus to prevent the abnormal consequences of the disease and to decrease the rate of mortality effective clinical and practical measures are required to diagnose the major predisposing factors involved in the pathogenesis of this 
disease(3). Both genetic and environmental factors have been considered as an etiology for T2D.It has been studied and reported that the Asian Countries particularly India and China in the next two decades will be having the major populations of Diabetes (45).According to studies carried out in Malaysia about $11.7 \%$ (2.1 million) of the adult population have diabetes (6). T2D is a complicated common endocrine metabolic disorder, characterized by insulin resistance and/or pancreatic $\beta$-cell dysfunction which in turn results from both genetic and environmental factors $(2,4,5)$. In about $2-12 \%$ of individuals with type 2 diabetes latent autoimmune diabetes of adults (LADA) occurs (7-10).In adult diabetic patients due to the presence glutamic acid decarboxylase antibodies (GADA), LADA can be distinguished (11).

In the recent few decades rapid changes in the prevalence of type 2 diabetes have been observed. These changes are due to the interaction of a stable genetic background with the rapidly changing environment(12). It has been proposed that the major driving force for the occurrence of type 2 diabetes is insulin resistance. The principal pathophysiological abnormalities leading to increased levels of blood glucose are impaired insulin action and impaired pancreatic insulin (13).These are present to varying degrees in almost all patients with the common form of T2DM. Insulin resistance is a common pathologic condition in which target cells fail to respond to the physiological effects of insulin occurring in peripheral organs and ultimately leading to abnormalities in glucose, lipid and protein metabolism (14). When the target tissue does not respond to even high levels of insulin, glucose builds up in the blood resulting in high blood glucose or type 2 diabetes. In fact, insulin resistance is present in the majority of patients with impaired glucose tolerance or T2DM, and it is also found in up to $25 \%$ of the general, apparently healthy population (15). The secretion of insulin from the pancreatic $\beta$-cells occurs in two phases. This is mainly regulated by the entry of glucose via its transporters. In nondiabetic subjects after the administration of glucose the insulin secretion is abundant and rapid, lasting for approximately 10 minutes to compensate for an acute postprandial glucose peak and this state is defined as the first-phase response. The second-phase of insulin secretion is the subsequent and sustained increase in insulin secretion which is slower and lasts longer. In T2DM, the first-phase secretion of insulin as a response to glucose is missing or considerably weakened (16). A secretory defect in the second phase is also characteristic of T2DM, and the ability of glucose to potentiate the effects of other stimulants of insulin secretion is diminished. In response to elevated blood glucose concentration due to insulin resistance, $\beta$-cells need to increase the insulin secretion to maintain homeostasis in glucose levels. Finally, $\beta$-cells become unresponsive to glucose due to pancreatic $\beta$-cells dysfunction and eventually type 2 diabetes develops. Although the etiology of the $\beta$-cell dysfunction of diabetes is incompletely understood, it is thought to result from both genetic and environmental factors (16). Eriksson and co-workers (2001) have postulated that, among individuals with type 2 diabetes, roughly half of their disease risk can be attributed to environmental exposure and half to genetics. Family history, diet, and lack of physical activity are all major risk factors for developing T2DM. Dyslipidemia and high blood pressure are other risk factors that often appear before the clinical disease is evident (17). Elevated levels of free fatty acids are also strong predictor of diabetes and correlate with hepatic glucose output, a major cause of diabetic hyperglycemia (18) high glucose levels, and obesity. Virtanen and Aro (1994) demonstrated in a case-control study that 60$80 \%$ of persons with T2DM are obese. 


\section{Genetic variants of T2D}

Type 2 diabetes (T2D) occurs as a combined result of multiple genes and multiple environmental factors with a high genetic predisposition to the disease. About 80 single nucleotide polymorphisms have been identified according to genome wide association studies (GWAS) ultimately conferring susceptibility to type 2 diabetes (T2D). In diverse populations most of these loci have not been replicated and much genetic heterogeneity has been observed across ethnic groups. However, most of the genetic variants that are validated are involved in $\beta$-cell function. In several studies an association between impaired $\beta$-cell function and $\mathrm{Zn}$ transport activity by SLC30A8 has been reported. According to the consensus SLC30A8 is crucial for insulin processing and secretion, and the major contribution of the SLC30A8 SNPs to T2D is mediated through defects in insulin secretion rather than action.

SLC30A8 gene located on 8q24.11 is one of susceptibility genes for T2D which has been studied by many research groups in different countries. SLC30A8 gene encodes a protein called Zinc transporter 8 that is a member of solute carrier major family proteins. The gene codes for a protein called Zinc transporter 8 that is a part of solute carrier major family proteins. This protein has six trans-membrane domains with histidine-rich loop between trans-membrane domains IV and $\mathrm{V}$ and consists of 369 amino acid residues like other members of cation diffusion facilitator (CDFs) (19-21). In the $\beta$-cells of the pancreas the gene shows a predominant expression with the major function of transferring zinc from cytoplasm into insulin secretary vesicles. These vesicles are quite important for the storage of insulin in bound form in association with $\mathrm{Zn}^{2+}$ ions in addition to the secretion also. Prior to the secretion of insulin, zinc seems to play an important role in translocation and synthesis of insulin. Zinc is one of the essential trace element and plays a key role in glucose metabolism. Zinc is an important component of many enzymes and it plays an significant role in the maintenance of several tissue functions (22). The relationship between diabetes, insulin and zinc is complex, with no clear cause and effect relationships. Zinc plays a clear role in the synthesis, storage and secretion of insulin, as well as conformational integrity of insulin in the hexameric form. It has the ability to regulate insulin receptor intracellular events that determine glucose tolerance and the ability to support a normal pancreatic reaction to a glucose $\operatorname{load}(23)$. Zinc prevents the destruction of $\beta$ cell and also has well known antiviral effects. The complications of diabetes may be mediated, at least in part, through oxidative stress, and zinc plays a key role in the cellular anti oxidative defense(24). Hence, it has been suggested that an abnormal zinc metabolism may play a role in the pathogenesis of diabetes and some of its complications.(25). Zinc has been found to enhance the effectiveness of insulin in-vitro and hence, a zinc deficiency may aggravate the insulin resistance in type II diabetes. This may cause complications. Antioxidant enzymes such as oxide desmutase, catalase and peroxidase require zinc.

In a study to assess the risk of offspring of diabetic patients being affected by diabetes, Boesgaard et al., found that in condition of SLC30A8 gene over expression, there is an increase in glucose induced insulin secretion in insolinoma cells. They found that mutations in the genes on specific sites result in reduced first-phase insulin release in nondiabetic offspring of type 2 diabetes patients. These studies ultimately determine that SLC30A8 gene encodes a protein that plays an important role in transfer of insulin within cells. These finding may result in a possible therapeutic approach with zinc supplementation or pharmacological 
manipulation of its transport within related cells, hence shedding light on important role of genetic elements on synthesis and secretion of insulin.

\section{Future research}

It is clear that SLC30A8 is a human gene that codes for a Zinc transporter which in turn is associated to insulin secretion in humans. SLC30A8 encodes zinc transporter-8 (ZnT8), which is responsible for transport of zinc ion from the cytoplasm into insulin granules. As the insulin granules contain high amounts of zinc, the physiological role of secreted zinc remains elusive. In diabetes there occurs disturbances in the levels of zinc an important trace element. Zinc plays a key role in the synthesis and storage of insulin molecule. Further it also seems to maintain the structural integrity of insulin. In the recent few years there is an alarming increase in the number of diabetic cases particularly in the urban areas. Further the onset of diabetes at a younger age poses a serious threat to the economy. Hence it has became very important to identify individuals early who are at risk of diabetes. Besides these facts appropriate intervention in the form of weight reduction, changes in dietary habits and increased physical activity could significantly help to prevent, or at least delay the onset of diabetes and thus reduce the burden due to non communicable diseases in India. Also additional studies needs to be carried out which could prove beneficial to the mankind in reducing the prevalence of this disease.

\section{References}

1. Meetoo D, McGovern P, Safadi R. An epidemiological overview of diabetes across the world. Br J Nurs, 16(16): 1002-7 (2007).

2. Esteghamati A, Gouya M.M, Abbasi M, Delavari A, Alikhani S, Alaedini F, Safaie A, Forouzanfar M, Gregg E.W.
Prevalence of diabetes and impaired fasting glucose in the adult population of Iran: National Survey of Risk Factors for Non-Communicable Diseases of Iran. Diabetes Care, 31 (1): 96-8 (2008).

3.Lindgren C.M, McCarthy M.I. Mechanisms of disease: genetic insights into the etiology of type 2 diabetes and obesity. Nat Clin Pract Endocrinol Metab, 4(3): 156-63 (2008).

4.Wild S, Roglic G, Green A, Sicree R, King H: Global prevalence of diabetes: estimates for the year 2000 and projections for 2030. Diabetes Care 2004,27:10471053.

5.Ng MC, Park KS, Oh B, Tam CH, Cho YM, Shin HD, Lam VK, Ma RC, So WY, Cho YS, et al.,: Implication of genetic variants near TCF7L2, SLC30A8,HHEX, CDKAL1, CDKN2A/B, IGF2BP2, and FTO in type 2 diabetes and obesity in 6,719 Asians. Diabetes 2008, 57:2226-2233.

6.International Diabetes Federation:Diabetes Atlas update $5^{\text {th }}$ editionedition.2012

7.Naik RG, Brooks-Worrell BM, Palmer JP: Latent autoimmune diabetes in adults. J Clin Endocrinol Metab 2009, 94:46354644.

8.Turner R, Stratton I, Horton V, Manley S, Zimmet P, Mackay IR, Shattock M, Bottazzo GF, Holman R: UKPDS 25: autoantibodies to islet-cell cytoplasm and glutamic acid decarboxylase for prediction of insulin requirement in type 2 diabetes. Lancet 1997, 350:12881293.

9.Monge L, Bruno G, Pinach S, Grassi G, Maghenzani G, Dani F, Pagano G: A clinically orientated approach increases the efficiency of screening for latent autoimmune diabetes in adults (LADA) in a large clinic-based cohort of patients with diabetes onset over 50 years. Diabet Med 2004,21:456-459.

10. Roh M-O, Jung C-H, Kim B-Y, Mok J-O, Kim C-H: The prevalence and characteristics of latent autoimmune diabetes in adults (LADA) and its 
relation with chronic complications in a clinical department of a university hospital in Korea. Acta Diabetolo 2010, 47:1-6.

11. Stenström $G$, Gottsäter A, Bakhtadze E, Berger B, Sundkvist G: Latent autoimmune diabetes in adults. Diabetes 2005, 54:S68-S72.

12.Petrie JR, Pearson ER, Sutherland C: Implications of genome wide association studies for the understanding of type 2 diabetes pathophysiology. Biochem Pharmacol 2011, 81:471-477.

13. Kahn, B.B., and Rossetti, L. 1998. Type 2 diabetes who is conducting the orchestra? Nat. Genet. 20:223-225.

14. White MF, Kahn CR: The insulin signaling system. J Biol Chem 269:1-5, 1994

15. Reaven, GM. Role of insulin resistance in human disease. Diabetes 1988; 37: 1595-607.

16.Pratley RE, Weyer C, Bogardus C: Metabolic abnormalities in the development of non-insulin-dependent diabetes mellitus. In Diabetes Mellitus. 2nd ed. LeRoith D, Taylor SI, Olefsky JM, Eds. Philadelphia, LippincottRaven, 2000, p. 548-557.

17.Groop L, Forsblom C, Lehtovirta M, Tuomi T, Nisse!n M, Ehrnstro\$m B-O et al., Metabolic consequences of a family history of NIDDM (The Botnia Study). Evidence for gender specific parental effects. Diabetes 45; 1585-93: 1996.

18.Bergman RN, Ader M. 2000. Free fatty acids and pathogenesis of type 2 diabetes mellitus. Trends

Endocrinol

Metab 11:351-356.

19.Gold G, Grodsky G.M. Kinetic aspects of compartmental storage and secretion of insulin and zinc. Experientia, 40: 11051114 (1984).

20.Emdin S.O, Dodson G.G, Cutfield J.M, Cutfield S.M. Role of zinc in insulin biosynthesis: some possible zinc-insulin interactions in the pancreatic B-cell. Diabetologia, 19: 174-182 (1980).

21.Dodson G, Steiner D. The role of assembly in insulin's biosynthesis. Curr Opin Struct Biol, 8: 189-194 (1998).

22 Zargar Abdul Hameed, Shah NA, Masoodi SR, Laway BA, Dar FA, Khan AR, Sofi F A, Wani AI. Copper, zinc, and magnesium levels in non-insulin dependent diabetes mellitus. Postgrad Med J. 1998;74(877):665-68. (PMC free article) (PubMed)

23. Chris Andrews. Zinc, Diabetes Mellitus and Oxidative Disease. A Nutritional 2005;22

24. Arthur B. Chausmer. Zinc, Insulin and Diabetes. Journal of the American College of Nutrition,1998; 17 (2): 10915.

25. V Rai, U Iyer, I Mani, U V Mani. Serum Biochemical Changes in Insulin Dependent and Non-Insulin Dependent Diabetes Mellitus and their Role in the Development of Secondary Complications. Int. J. Diab. Dev. Countries 1997; 17.

\section{How to cite this article:}

Fasil Ali, Aarif Ali, Showkeen Muzamil, Omer Khalil Baba, Aadil Ayaz and Mashooq Ahmad Dar. 2017. Gene Polymorphism of Solute Carrier 30 A8 (SLC30A8) in Type 2 Diabetes Mellitus. Int.J.Curr.Microbiol.App.Sci. 6(9): 3562-3566. doi: https://doi.org/10.20546/ijcmas.2017.609.438 